\title{
Análisis histórico conceptual de la política desde la transdisciplinariedad
}

\section{Conceptual historical analysis of political theory from transdisciplinarity}

\begin{abstract}
Rafael Vergara Varela'
1 Doctorando en Administración de la Universidad del Valle. Correo electrónico: rafael.vergara@correounivalle.edu.co

\section{JUSTICIA}

ARTÍCULO DE

INVESTIGACIÓN

Recibido: 03-08-17

Aceptado: 03-09-17

Publicado: 18-01-18

Dol:

https://doi.org/10.17081/ust.23.33.2888

\section{RESUMEN}

Este documento de trabajo busca analizar y estudiar la teoría política para entender los pactos del Estado con la sociedad, y de igual forma entender holísticamente el conocimiento propuesto de los autores aquí reseñados, como también el entorno espacio-temporal en el que se enmarcan estas ideas y sus efectos en la sociedad. Evidentemente el discurso desde las Ciencias Sociales hoy involucra a la temática posmoderna de la transdisciplinariedad. Por ello, desde este enfoque el artículo busca responder una pregunta transversal que guía al estudio en torno al devenir histórico de la teoría política. Empero este trabajo es una aproximación a la temática.

Palabras clave: Contractualismo, postmodernidad, transdisciplinariedad y teoría política.

\section{ABSTRACT}

This working document seeks to analyze and study political theory to understand the covenants of the State and society, and similarly holistically understand the proposed knowledge of the authors reviewed here, as well as the environment temporary space in which these ideas are framed and its effects on society. Obviously the speech from the Social Sciences today involves the postmodern theme of transdisciplinarity. Therefore, from this approach article seeks to answer a question that guides the transversal study about the historical development of political theory. But this work is an approach to the subject.

Key words: Contractualism, postmodernism, transdisciplinarity and political theory.
\end{abstract}




\section{INTRODUCCIÓN}

Hoy la filosofía política o la teoría política está siendo presentada desde el contexto unidisciplinar como un cuerpo de análisis y discusión en torno al sujeto político y su sociedad como formas de debate sobre los cuestionamientos del accionar del Estado y sus políticas a la sociedad. Empero, la propuesta de este documento se enmarca en un estudio holístico sobre la teoría política desde el análisis discursivo y su relación con el entorno en una consideración de orden transdisciplinar.

Por ello el documento tiene tres apartes, donde la primera parte presenta el significado de la transdisciplinariedad con la ciencia social y cómo desde allí se va a leer este documento de trabajo. En la segunda parte se realiza el abordaje transdisciplinar de la teoría política relacionado con el mundo antiguo y medieval, la modernidad y el postmodernismo. La tercera parte plantea las conclusiones en torno a estas temáticas.

Por lo tanto, la pregunta que guía transversalmente este ejercicio analítico sobre la teoría política es: ¿Cómo han sido los acuerdos de la sociedad con el Estado en su larga duración histórica? La respuesta a esta inquietud se encuentra en el documento mismo en relación al debate y la discusión de los autores reseñados aquí. Bajo el enfoque propuesto se busca articular la orientación y el sentido del lector en torno a los acuerdos de la sociedad y el Estado en una versión de larga duración de carácter histórico-integral.

\section{LA TRANSDISCIPLINARIEDAD EN LAS CIENCIAS SOCIALES}

Desafortunadamente las ciencias exactas, sociales y humanas (en general), han desarrollado sus estructuras académicas desde la dialéctica monodisciplinar como islas, donde el diálogo de saberes no existe y el abordaje de los problemas no involucra holísticamente a ningún programa académico dentro de los esquemas universitarios tradicionales. Empero el modelo contemporáneo de investigación no satisface este tipo de escenarios, los cuales tienden a ser bastante anacrónicos y deslegitimados.

Históricamente esta estructura monodisciplinar inicia con la escolástica en el medioevo hasta la era del racionalismo cartesiano o desarrollo de la ciencia moderna (Gusdorf), donde la transformación social requería nuevas formas de interacción. Entre esas formas de interacción el hombre está creando todo el tiempo cultura ${ }^{2}$, como referente tomamos por ejemplo, que la sociedad

2 Desde el análisis marxista el hombre se configura y se compagina con la historia creando cultura, lo cual es representado por el materialismo histórico donde se describe a la historia de la sociedad desde sus diferentes modos de 
moderna hizo la transición entre el feudalismo hacia la sociedad del capital, es decir, donde estamos pasando de pequeños talleres artesanales a la fabricación bajo esquemas de división del trabajo, por lo tanto en esta versión integral nuevas formas se institucionalizan, entre ellas las jornadas de trabajo, las estructuras organizacionales, la conformación social, capitalistas vs proletarios, etc. Es en este objeto en que la interacción social está construyendo nuevo conocimiento científico y nuevo orden social en una versión construccionista de la realidad.

Como bien plantea Edgar Morin (s.f.), la fecundidad de la ciencia permitió la transición e interacción de discursos monodisciplinares a objetos de estudios que construyen un sentido o una acción, es decir, crearon un lenguaje, rompiendo la frontera monodisciplinaria en relación a los problemas que discutir, lo que significa que desde estos lenguajes las diferentes disciplinas insulares crearon nuevo conocimiento argumentativo y complementario que a la vez tendía a ser un poco difuso en el riesgo de la hiperespecialización.

Al respecto, se ha meditado sobre los problemas de la sociedad moderna, en la cual los jóvenes se traslucen por intermedio de los contextos de la universidad, donde a pesar que las disciplinas existen, el modelo se sustenta sobre la dispersión disparatada del positivismo de las ciencias, esto significa que hoy la interdisciplinariedad responde más a la autonomía de las ciencias o epistemes en la sectorización del poder disciplinar. Por lo tanto, estamos hablando entonces que en muchos contextos educativos, sociales e institucionales el diálogo participativo, interactivo y constructivo de saberes no existe por el exceso de feudalización del artificio de la mente humana.

En complemento a lo planteado en el párrafo anterior, y desde el discurso dialéctico monodisciplinar se entendería entonces que la construcción epistemológica de la ciencia social tecno-racional instrumental se remonta a un siglo (aproximadamente) tanto en Norteamérica como en Europa. De hecho, si analizamos y tomamos como ejemplo la modernización, la burocratización y la revolución industrial, debería proponerse entonces que la estructura managerial primigenia es en esencia bastante "pragmática" en función u objeto de su instrumentalización, dado que en su ideario, en su conceptualización como en su estructura metodológica fue descrita y hecha por ingenieros en un esquema tecnocientífico de prácticas productivas para un fin específico dentro de una cadena productiva en una planta o taller, en un sistema indus-

producción: asiático, esclavismo, feudalismo y capitalismo. Es decir, el hombre es un ser social por naturaleza con lo cual además transforma su naturaleza en aras de resolver sus propias necesidades, con lo cual en cada estadio histórico se crea cultura. 
trial o una organización empresarial, prueba de ello es el corpus argumentativo a través de lo que se denominó el primer management tratados de "administración científica".

Es decir, la noción ontogenética de dirección-administración se articuló y se contextualizó en un primer momento en los escenarios ingenieriles cuyo corpus cultural se adecuó alrededor del contexto interno de las fábricas, por lo tanto se fue creando un sentido y un significado jerárquico de orden y obediencia, en últimas un lenguaje, que determinó una cultura instrumental de un orden de máximo rendimiento en el cual incumplir en la producción es sinónimo de pereza, la cual fue en esencia totalmente castigada. En síntesis, el discurso primigenio del management fue de orden unidisciplinar. Sin embargo, en el orden argumentativo de este documento cabe hacerse aquí la siguiente pregunta: ¿desde el punto de vista discursivo disciplinar, hacia donde tienden las Ciencias Sociales incluida la teoría política hoy? Esto significa que la construcción dialéctica en el buen sentido hegeliano debe dar una respuesta al final de este documento ${ }^{3}$.

Ahora, la respuesta que se guía por la pregunta (del párrafo anterior) se estructura desde el discurso de Max Neef (1996) en cuanto al orden estructural de "aclaración de conceptos", es decir, la respuesta a los problemas debe ser el resultado de la interacción dialógica de disciplinas como un aporte holístico a la problemática que se quiere intervenir o estudiar. Asimismo, Alain Chanlat (1984) plantea que el enfoque multicomplementarista concilia el saber y la acción, por lo tanto, la ciencia no puede ofrecer una visión simplificada de la realidad sino que en el completex de los fenómenos estos deben ser reales y explicables a través de sus propios marcos de referencia.

Por ello dentro del análisis de la usurpación y migración interdisciplinaria planteada por Edgar Morin (s.f.), este se enfoca en que es esencial la ruptura de las fronteras disciplinarias, es decir, la usurpación de un problema de una disciplina sobre otras disciplinas, ello implica la evolución o la escogencia de escenarios (multi, pluri, inter y trans) respecto al contexto integrado de las disciplinas, sin ello querer implicar que debe obedecer a un contexto de orden secuencial.

Si bien, los enfoques metodológicos multi, pluri e interdisciplinarios han demostrado la resolución de problemas sin coordinación entre las disciplinas

3 Hay que recordar que la propuesta hegeliana presenta una metodología secuencial dada como tesis, antítesis y síntesis, ahora siendo coherente con ello, podría decirse también que el discurso metodológico en las Ciencias Sociales hoy ha evolucionado alrededor de lo monodisciplinar y pluridisciplinar, hacia lo transdisciplinar. 
manteniendo esquemas unidisciplinares. Sin embargo, para los enfoques interdisciplinarios la coordinación sigue obedeciendo un marco referencial respecto a una disciplina que los integra muy similar a un esquema jerárquico donde existe una estructura y una superestructura. Frente a esto, Morin define la interdisciplinariedad como una respetada autonomía de las ciencias. En últimas, la interdisciplinariedad es el estudio de un fenómeno u objeto analizado por otras disciplinas de orden similar, es decir, su orientación es guía definida si tiene un orden superior propositivo entre disciplinas o un orden superior normativo entre políticas.

Por otra parte, empieza a tomar relevancia en el estudio de las ciencias en general, el término transdisciplinariedad, el cual es el resultado entre la adición entre el nivel propositivo, el nivel normativo y el nivel de los valores, es decir la transdisciplinariedad responde a un conjunto integrado de valores, normas y ciencias disciplinares en un contexto complejo donde cada parte no es independiente de las demás sino que es el resultado agregado de una estructura no lineal que busca la respuesta más holística a un problema, donde su respuesta es la integralidad. Dicho de otra forma, donde los aspectos éticos, normativos y disciplinares cobran sentido a través del lenguaje, es decir, es la creación institucional desde diferentes contextos (Aktouf, 2000).

Frente a la pregunta de la página anterior se debe plantear que hoy más que nunca las Ciencias Sociales y Humanas han trascendido de un enfoque multidisciplinar a objetos de estudio en el orden transdisciplinar donde los bienes materiales, inmateriales y sociales juegan un papel holístico en la generación intra y extraorganizacional de la relación cultural del hombre en la sociedad.

\section{LA POLÍTICA, EL MUNDO ANTIGUO, EL MEDIEVAL Y EL DEMO- LIBERAL}

Si analizamos a la transdisciplinariedad como el diálogo interactivo y constructivo de saberes disciplinares de conocimiento, entenderíamos entonces con mayor precisión que el concepto de burocracia es un término más bien reciente si se analiza la historia del hombre en su larga duración histórica. Empero el sujeto político aparece desde el desarrollo de la modernidad histórica que a juicio de diferentes autores se contextualiza y se identifica que el desarrollo de Occidente inició en la Grecia antigua. Es decir, el mundo antiguo ateniense ya expone a un sujeto que se reafirma en su individualidad (Vernant, 2001). Además nuestras formas de pensar responden a las reglas del lenguaje y las formas que nos gobiernan, todo es producto de la antigüedad, de hecho Jenofonte ya habla implícitamente de la adminis- 
tración como una forma de instruir sobre la dirección eficiente y el liderazgo (Gomperz, 1955, p. 528).

Desde el contexto espacial mediterráneo se entiende que geográficamente el territorio de Grecia es un conjunto de islas donde Atenas es el epicentro o el círculo unitario convergente de la política y de lo político, a partir de este núcleo se desarrolló la filosofía política antigua, y es a partir de esta identificación geográfica donde se edifica el imaginario sobre la ciudad o la polis como el eje articulador de la estructura socio-política y económica del Estado griego. Por ello, Aristóteles (2001) en su libro primero se refiere a la comunidad y a la ciudad como también a la familia y a la aldea, esto significa en términos taulógicos que la familia es la base de la comunidad, en consecuencia, la aldea es la base de la ciudad. A partir de aquí la polis y la sociedad griega generan reglas, orden y jerarquías. Sin embargo, se debe establecer que Grecia antigua es una sociedad de orden tradicional centrado en el hombre (lo masculino), a tal punto que el hombre gobierna y la mujer obedece.

Dentro del contexto territorial, la ciudad es un aspecto relevante para el Estado griego, pero socialmente la cuidad puede variar de acuerdo con la categoría de ciudadano, y su asociación, pues su conceptualización varía de acuerdo a como moran los vecinos, al linaje de las gentes, así como al cambio en la comunidad, lo cual cambiaría la representación de la ciudad, incluso del gobierno. En cuanto a esto, Aristóteles (2001) al vislumbrar al ciudadano entra a diferir entre la virtud del buen varón y el buen ciudadano, para el primero plantea que esta no es común en todos ya que sus condiciones de partida son diferentes, mientras que para el segundo, su virtud tiene como fin la conservación de la comunidad, y es para todos; cabe destacar que la virtud hace referencia a su oficio.

Posteriormente, Aristóteles (2001) entra a definir el fin de la ciudad como conservar la comunidad, el provecho mutuo, así como diferencia los diferentes tipos de gobierno, aristocracia, oligarquía, democracia, etc ${ }^{4}$. Con respecto, a la división de los gobiernos plantea cuáles son buenos y cuáles viciosos, entre los primeros clasifica a la monarquía, la aristocracia y el público gobierno o la república; en los segundos categoriza a la tiranía, la oligarquía y la democracia; en los cuales plantea que existe un disentimiento de clase sobre sus perspectivas sobre la justicia, la verdad y el derecho político.

4 Aristóteles (2001) hace referencia a las maneras de gobierno, partiendo de la concepción que cada una tiene sobre el ciudadano, y consecutivamente a la ciudad; destacando al final que la aristocracia es la mejor forma de gobierno, pues no recae en vicios como la oligarquía, por la perspectiva de pocos, o la democracia por la de muchos, así como la monarquía dado que termina siendo tiránica con gobiernos señoriles. 
De otra parte, Aristóteles (2001) explica la acción del Estado y el deber ciudadano, categorizando lo justo e injusto de acuerdo al gobierno, ya que este es quien conceptualiza los hechos; de igual modo, entrar a plantear en qué debe residir la soberanía en los diferentes gobiernos, destacando que para todos en su deber ser, debería de ser de acuerdo a las determinaciones y conforme a lo que cada uno determine residir en las leyes. Otro de los temas que resalta Aristóteles en el libro Política, es cómo repartir las magistraturas entre los ciudadanos, la cual se debe repartir de acuerdo con sus semejanzas para que no haya diferencias con respecto a la concepción de justicia, por lo que su igualdad hará referencia a aquellas cosas que constituyen la ciudad.

Por otra parte, se debe agregar también en medio de la contextualización antigua que la sociedad griega es igualitaria, no tiene castas; ni religiosa, ni militar. La urbe o la polis integra a sus ciudadanos en un mismo plano salvo a los esclavos que están por fuera de la humanidad. En Grecia el sujeto se integra a lo religioso, a lo político y a lo social. Esto significa que es un agente sujeto de derecho, político y persona privada. Por lo tanto, el ciudadano griego es sujeto político-racional que actúa, delibera y participa en el ágora (Vernant, 2001). Desde lo político el sujeto de la polis vive un mundo de iguales siempre y cuando se le considere al otro como ciudadano (sustancia común) ${ }^{5}$ y sociológicamente hablando los siervos y los esclavos están en las capas más bajas de esta sociedad por ello están por fuera de la ciudad.

Al respecto, basta recordar que la sociedad griega planteó dos ideas de individualismo. Una determinada por el gobernante autoritario que tenía el poder para tomar decisiones administrativas para el interés social. La otra conceptualización se determinó al desarrollo del ciudadano individual, quien tomaba decisiones. Estos dos conceptos contribuyeron a la formación de la sociedad griega sobre la idea de "la administración".

Por ello, retomando nuevamente a Jenofonte, este expresó sus ideas en términos del individuo que toma decisiones, es decir, su discurso se centró en la capacidad humana planteada por un buen liderazgo como objeto principal de la administración. El liderazgo en Jenofonte implica que un buen administrador se esfuerza por incrementar el excedente de la unidad que coordina, ya sea la familia, la ciudad o el Estado y esto se logra a través de la habilidad, el orden y la división del trabajo.

5 Para Aristóteles (2001), el cuestionamiento central sobre el ciudadano se refiere a quien tiene derecho y libertad de participar del gobierno, del consejo y de la judicatura. 
En síntesis, para Aristóteles (2001) la concepción de la economía se contextualiza, se armoniza y se compagina con la idea de Jenofonte, es decir, la conceptualización de economía se centra en la administración de la casa y al administrar la casa se puede administrar el gobierno de lo público. Por ello, para Aristóteles las tres partes de la economía son: la disciplina señorial, la paternal y la conyugal. El gobernar presenta su dificultad, pues en cuanto a la casa el hombre tiene que saber qué requiere cada cual al que rige, sea siervo, mujer o hijos; en la República debe pretender la igualdad, marcando las diferencias que lo hace regir, ya que quien manda y quien obedece han de tener diferentes virtudes, siendo quien gobierna el que tiene una virtud moral perfecta, mientras los demás la tendrán de acuerdo a su rol y oficio, incidiendo en esto el señor desde su disciplina señoril.

Desafortunadamente en la Edad Media en la era del siglo cristiano, las formas de lo político y la política cambian sus reglas dado que las sociedades europeas (específicamente Inglaterra) están pensando cómo hacerle frente a los ataques del enemigo sean estos el imperio turco-otomano, los mongoles, o los bárbaros, donde las pequeñas villas o los feudos requieren inminentemente de la seguridad de parte de una autoridad con bastante poder que les brinde la calma en sus territorios que se han contextualizado metafóricamente en el estado de la naturaleza, ${ }^{6}$ y su respuesta a ello reside en el Leviatán.

En este aspecto caótico de estas sociedades, se erige a Hobbes (2000) como uno de los teóricos filosóficos más relevantes en la descripción de los problemas políticos en la sociedad medieval y su resolución a través de los acuerdos societales con el monarca como una forma de resolver la paz negativa o el conflicto. En Hobbes (2000) y su relato sobre "el Leviatán" se hace una argumentación en defensa de la monarquía absolutista como una regla social que ayuda a preservar la paz en el Estado como sinónimo de bienestar general.

Bajo el esquema hobbesiano, se condiciona a la sociedad frente a un jefe supremo coercitivo que resuelve los problemas de la sociedad, a tal punto que los ciudadanos obedecen y legitiman al soberano al depositar en el gobernante la confianza de su máxima autoridad con lo cual se genera todo un escenario que históricamente se conoció como el absolutismo o los regímenes absolutistas. En esta versión política del mundo el monarca asume todos los poderes para guiar al Estado.

6 Esto significa que el hombre es un lobo para el hombre. 
Y en esta preformación de los estados nacionales la seguridad es la característica principal en el contexto económico y social. Por ello, se fortalece el comercio interno y externo de los territorios, esto significó una pieza fundamental para el desarrollo del mercantilismo económico del medioevo, dado que para el gobernante al asegurarse las ganancias del comercio fortalecía de igual forma al Estado, por ello la máxima del principio económico gravitó en torno a las balanzas comerciales favorables (lo cual reside en que las exportaciones deben ser mayores que las importaciones), técnicamente esto implicó que se acumulaba mayor dinero (fruto del comercio), el cual estaba representado para la época a través de los metales preciosos como el oro y la plata7. Es decir, los poderes del monarca autoritario ${ }^{8}$ hacen vislumbrar inclusive en la política económica.

Para Hobbes (2000) el monarca autoritario o Leviatán es un sujeto que busca su propio beneficio, su propio bienestar mediante la coerción como una manera de mantener el orden. Y mediante estas acciones la sociedad se armoniza, dado que los sujetos cumplen las funciones de un siervo-esclavo (en este contexto al hombre se le asemeja como un animal o una bestia dado que requiere de un amo-soberano para pacificarle, amaestrarle o sacarle del estado de naturaleza). En últimas, lo que se demuestra es que el poder no es divino ${ }^{9}$, es de carácter humano y terrenal. En conclusión, como diría Marx (2002), el hombre es un ser social por naturaleza, tan social es el sujeto humano que acuerda y acepta pactos, es decir, la nueva era del contractualismo se puede vislumbrar desde aquí.

Por otra parte, desde el análisis de contexto sociológico se encuentra que en el medioevo específicamente en el mundo feudal, el individuo en la sociedad política es un sujeto restringido en derechos, dado que el orden social se define entre señores y siervos atados a un feudo (bajo relaciones de dependencia). Desde el enfoque eurocentrista, el orden implica un llamado al mundo, a la civilización y al reconocimiento del individuo. Es también un llamado al orden de las instituciones. El orden feudal es bastante controlador y excluyente en relación al poder, además orgánicamente se desarrolla bajo un esquema piramidal en relación a sus jerarquías, es también por eso que su mundo se edifica cerrado por medio de fortalezas que sirven para protegerse de las agresiones del enemigo externo (Duby, 2001).

7 Esto explica cómo España se convirtió en un imperio después del descubrimiento de América.

8 El monarca autoritario descrito por Hobbes es el "Leviatán" al cual se le teme como a un diablo y se concibe como a un dios.

9 Se debe recordar que Inglaterra en medio de la contextualización de Hobbes, está haciendo la transición a una sociedad religiosa de carácter protestante anglicana, con lo cual buscan desmitificar todo lo que proviene del catolicismo, como la explicación del tema del poder impuesto desde arriba. 
La emergencia de este individuo político se hace evidente cuando se desarrolla el mundo económico porque es a partir de allí en que se generan las nuevas reglas del juego para la sociedad. Instituciones que regulan y reconocen la participación del sujeto como ciudadano político y económico en la sociedad (homo economicus). En últimas, en la medida en se genere la transición del feudalismo al capitalismo (Dobb, 1971). Es decir, cuando la autoridad y el poder dejen de ser de carácter tradicional por herencia patriarcal a una sumisión que se categorizó como racional (en relación de medios a fines).

Valga la pena anotar que de hecho el siglo XVII está presentando una transformación de origen económico que se conoció como la transición de los talleres artesanales a la construcción en serie, es decir, al surgimiento de las pequeñas fábricas, ocasionado y explicado por el fenómeno de la acumulación, el cual provenía del comercio y que dejaba ingresos como también dividendos que eran reinvertirles en los burgos. De ahí (de los burgos), toma su nombre una nueva clase emergente con poder de negociación e influencia política en la aristocracia y en las monarquías. Es decir, los burgueses es la nueva clase social, económica y política que influenciará las nuevas reglas del juego de carácter institucional liberal para la expresión y libre participación en la toma de decisiones en el Estado (la política), la expansión del mercado y la maximización del capital.

De igual manera, esa transformación paradigmática se está generando desde lo político donde el absolutismo como autoritarismo de Estado está siendo remplazado o va a empezar a desintegrarse, a descontextualizarse y a remplazarse por el reconocimiento de la libertad (ideológica, institucional, política, económica y social) bajo una arquitectura holística que desconcentre los viejos poderes monárquicos del modelo hobbesiano hacia un esquema de división de poderes (es decir, un modelo político de democracia representativa). Bajo este enfoque e influjo demo-liberal aparece en escena John Locke (1990), como uno de los fundadores del pensamiento liberal inglés, cuya ideología (en conjunto con Rousseau) sirvió de base para los movimientos independentistas en el continente colonial americano de los siglos XVIII y XIX.

Locke (1990) en su libro sobre el segundo tratado del Gobierno Civil, critica las estructuras radicales del absolutismo y el estado de la naturaleza de Hobbes, para Locke (1990) el Estado de Naturaleza no es un estado de guerra sino todo lo contrario es un estado de libertad perfecta pero que requiere de regulación institucional que haga más armoniosa la cooperación racional entre sujetos 
(para garantizar que los derechos naturales ${ }^{10}$ se cumplan mediante el contrato o acuerdo social). Hay que entender que su modelo empirista de la sociedad determina que el hombre es un ser racional y que su racionalidad va ajustada por su razón, por lo tanto, va sujeta a unos grados de libertad que permiten ejecutar las reglas del juego operantes y amparadas vía regulación.

Bajo este mismo juego metafórico de palabras, la economía como ciencia al igual que la política determinó que los sujetos en sociedad son seres (pensantes) racionales autónomos, que toman decisiones coherentes (dado que maximizan su utilidad o beneficio y minimizan su costo de oportunidad), que tienen relaciones armoniosas que las determina el mercado a través del libre juego de la oferta y la demanda, y que sumado a ello, el Estado no puede intervenir la economía sino todo lo contrario que hay que "dejar hacer y dejar pasar" (laissez faire-laissez passer). Asistimos entonces al debate del liberalismo promulgado por Locke (1990), este es por demás, uno de los grandes autores pioneros liberales en la ciencia económica), por lo tanto, desde su punto de vista político la soberanía radica en la sociedad civil ${ }^{11}$. Ahora mediante las nuevas reglas se requiere un poder civil que garantice y armonice las relaciones de esta sociedad civil, como respaldo absoluto de la libertad, entonces como se puede notar el juego metafórico está presente en el esquema del paradigma demo-liberal.

Por su parte, Rousseau (1989) plantea un discurso político alrededor del pacto con la sociedad, es decir, el poder soberano radica en la sociedad, por lo tanto, es un pacto democrático tal cual ocurrió en Francia en la época de la revolución (julio de 1789) donde la sociedad civil se convocó como el Estado (tercer Estado). En este pacto o contrato social el hombre tomo la decisión de enajenarse (su libertad natural) a cambio de una libertad civil, es decir, la ley hace parte de la voluntad general (la decisión de la sociedad), por lo tanto, su bien común. El contrato social de Rousseau es consistente equidistributivamente dado que invita a la sociedad a ejercer su poder de decisión en una igualdad común en términos políticos, es decir, un llamado a la soberanía popular en aras de la libertad. A grandes rasgos se puede pensar que a través del ideario político de los contractualistas como Rousseau (1989), Locke (1990) y Hobbes (2000) se puede observar perfectamente una tríada alrededor de tres aspectos fundamentales y claves en ellos (en clave paradig-

10 Los derechos naturales implican que todos los hombres nacen libres e iguales ante la ley y además los sujetos tienen relaciones vinculantes y obligatorias para preservar la armonía del acuerdo societal.

11 Para Locke (1994) el Estado surge como un pacto, un contrato o un acuerdo de la sociedad civil, en aras de la racionalidad que implica el orden en un contexto de civilización en la lógica de la modernidad. 
mática del contractualismo de los autores clásicos), es decir, hay una tríada implícita en ellos: la sociedad, el mercado y el Estado.

A partir del origen y desarrollo del capitalismo ${ }^{12}$ el hombre se convierte en "configurador de mundo", dado que se instala en el nuevo universo de los grandes meta-relatos como el progreso, el ascetismo, la ganancia, el bienestar, la justicia y la igualdad, etc., todo esto sustentado a través del lenguaje, la razón y la cultura (Agamben). Ahora, lenguaje y cultura son el objeto de instrumentalización del mundo, de un mundo donde el hombre sale del arquetipo feudal y se instaura en la transformación material de ese mundo (materialismo histórico de Marx), a través del cual, la especificidad humana evoluciona de un taller artesanal donde el sujeto lo hace absolutamente todo, a la transición de la producción en masa bajo las nuevas reglas de la división del trabajo y la plusvalía.

Asimismo se genera también la transformación cultural mediante reglas, o normas que permitieron esos grandes cambios convertidos en relatos duales tales como campo-ciudad, religión-trabajo, ricos-pobres, feudalismo-capitalismo, Estado-nación, obreros-capitalistas, amo-esclavo (Hegel), nobleza-clase social, taller-fábrica, etc. Es un nuevo orden social donde el sujeto queda atrapado en los esquemas de la industrialización, atrapado en una jaula de hierro al mejor estilo de Kafka (1980) en su relato de la metamorfosis. "Cuando Gregorio Samsa se despertó una mañana después de un sueño intranquilo, se encontró sobre su cama convertido en un monstruoso insecto" (p. 5). Este nuevo sujeto político que también es organizacional es un sujeto atrapado, es un sujeto burocrático kafkiano-pragmático-instrumental ${ }^{13}$.

\section{EL DISCURSO POLÍTICO DE LA MODERNIDAD, EL CONTEXTO BUROCRÁTICO Y POLÍTICO}

Ahora bien, los orígenes como la estructura epistemológica del management se remontan a un siglo (aproximadamente) tanto en Norteamérica como en Europa. De hecho, la estructura managerial primigenia es en esencia bastante "pragmática" en función u objeto de su instrumentalización, dado

12 Debe entenderse también que ese origen del capitalismo fue brutal y fue el soporte de los esquemas de la colonización mundial, como bien Marx plantearía en EI Capital-capítulo XXIV; "El Capital viene al mundo chorreando lodo y sangre". Esto explica la larga historia de los países desarrollados explotando a los países subdesarrollados y de esa forma se apropian del capital; ayer los metales preciosos (oro y plata), hoy la industria extractiva (el petróleo).

13 Desde el punto de vista histórico, el pragmatismo filosófico tiene una profunda conexión con los procesos de cambio técnico y managerial específicamente en relación a la segunda era de la industrialización que se desarrolló en Estados Unidos de Norteamérica (esto tiene cierta lógica, debido a que esta corriente de pensamiento filosófico se fundamenta en su carácter instrumental, lo que implica en esa relación lógica-matemática al mejor estilo de Pierce, se entendería que el instrumentalismo germinal managerial sirvió de base a la estructura y al sostenimiento del capitalismo). 
que en su ideario, en su conceptualización como en su estructura metodológica fue descrita y hecha por ingenieros en un esquema tecno-científico de prácticas productivas para un fin específico dentro de una cadena productiva en una planta o taller, en un sistema industrial o una organización empresarial, prueba de ello es el corpus argumentativo, a través de lo que se denominó el primer management: tratados de "administración científica"14.

La administración científica es un contexto que está siendo llevado a múltiples escenarios incluida la política a través de los esquemas de Gobierno, donde la planeación es su variable fundamental, por ello la planeación técnica de origen keynesiano es el instrumento principal dentro de los modelos de bienestar de la década del treinta del siglo XX y que fueron la alternativa a la crisis del capitalismo (1929) como además se erigió como el modelo imperante en el nuevo orden mundial para la administración pública.

Por su parte y desde la administración privada, cabe destacar que Henry Fayol tiene una propuesta diferente (de tiempos y medidas) que el Fordismo y el Taylorismo impusieron y apropiaron en los inicios del management, sin embargo el modelo fayolista se concentra en la instrumentalización operacional en el ciclo del management dentro de los esquemas de planificación organizacional, los cuales se circunscriben a través de: planear, decidir, ejecutar y evaluar, siendo este su postulado fundamental. Así mismo, este modelo planificador de orden circular por etapas en la década de los cuarenta del siglo XX para analizar el ciclo de la política pública en la administración pública. (Modelo propio, estructural y actual del management público).

Es por ello que el equilibrio en el management es statu quo, lo que significa que es funcionalidad del sistema, es funcionalidad del mercado, es funcionalidad de las lógicas poder; es bastante político discursivo. En últimas, es un equilibrio de carácter organicista-homeostático (dado que el funcionalismo era una ingeniería gradual de ajuste societal), básicamente los dispositivos del management son pragmático-universales y apuntan a cuestiones como: la eficiencia, la eficiencia-eficacia, tras los tópicos contemporáneos de competitividad, innovación, productividad y rentabilidad (esto es política), es decir, como plantea Omar Aktouf (2001), "el management es un brazo armado del economicismo", ejemplo de ello es el marketing, en últimas, la eficacia económica managerial sigue siendo dominante.

14 Aktouf (2001) plantea que el término administración científica es un abuso del idioma porque no se puede atribuir un carácter cientííco a una subdivisión, repartición y control del trabajo. Asimismo, el ejercicio de Taylor tampoco correspondía a los requisitos de la ciencia sino a las exigencias de incrementar la producción en las fábricas. No se debe confundir con ciencia al incremento laboral en la planta. 
El management más allá de su narratividad lineal que la tiene, es una gramática del poder, es una gramática de la instrumentalidad, es una gramática de las prácticas manageriales, es una discursividad atada a las prácticas manageriales y no es deductiva (es la realidad experiencial), es empirismo radical no es positivismo. El pragmatismo entiende lo real a partir de su representación. Todo pensamiento es conciencia y es acción (yo no puedo reflexionar si mi pensamiento no significa acción), es decir, se debe separar la decisión de la acción, en la retórica de la gestión pública; los Directivos (y/o Gobernantes), "los sujetos políticos" deciden, los mandos medios (burócratas) y bajos de la organización ejecutan (la sociedad legitima la autoridad), en conclusión, es pragmatismo.

De otra parte, Max Weber (1995) expresa sobre la vocación del político, describiendo su tipología planteando su surgimiento y la posterior evolución del funcionario como figura histórica, el cual tiende a vivir de la política o para ella, siendo esta una empresa de dominación; iniciándose mediante esto una distinción en cuanto a los medios necesarios para trabajar en dicho ámbito. Así en medio de la clasificación realiza una breve exposición sobre el proceso de especialización de la burocracia, las características, los medios y fines, que se tienen en cada tipología según el momento histórico al que pertenece; expresando a la vez la importancia del poder, al ser este el medio para conseguir ciertos fines; y al ser el fin que pretende conseguir el político, de acuerdo con la tipología a la que pertenezca.

Retomo nuevamente que a partir del origen del capitalismo al hombre o al ser humano lo convirtieron en "configurador de mundo", dado que se lo instaló y se le hizo creer en el nuevo universo metafórico de los grandes meta-relatos como el progreso, el ascetismo, la ganancia, el bienestar, la justicia y la igualdad, etc., todo esto sustentado a través del lenguaje, la razón y la cultura (Alveson, 1993). Ahora, lenguaje y cultura son el objeto de instrumentalización del mundo (por ejemplo, el concepto del ascetismo en Weber para justificar el desarrollo del capitalismo mediante la religión protestante).

Con esto se quiere expresar que el contexto burocrático se justifica en su mayor expresión durante el inicio de los modelos de bienestar (proteccionismo estatal) con su enfoque político utilitarista donde el concepto de lo público tiene mayor relevancia, lo que significa que lo público es para todos (sin exclusión).

Ahora dentro de este contexto del proteccionismo estatal con enfoque bienes- 
tarista convergieron movimientos políticos como el socialismo centro, la socialdemocracia, los partidos cristianos, pero llama la atención que en la Alemania de los años treinta del siglo XX empieza a conformarse una postura política que revive el constructo del origen germano a la figura de Bismark y que se conoció como el nacionalismo. Antes de explicar qué fue el nacionalismo como también sus consecuencias, se debe conocer primero sus orígenes estructurales en este estudio transdisciplinar de lo político.

Se entiende por vitalismo como aquella posición filosófica que convalida un principio vital, que consiste en la existencia de una fuerza o impulso sin la cual la vida no podría ser argumentada o explicada. Además la postura vitalista explica que los organismos vivos se distinguen de los inertes porque tienen una fuerza vital que no es física, ni química, es decir, la fuerza vital no debe ser estudiada de forma empírica.

En clave del vitalismo, el management posterior al fordismo y a la administración científica ingenieril de los años treinta, se integró con los aportes sociológicos ${ }^{15}$. Es un modelo dicotómico de lo no humano sobre lo humano, cuyos alcances establecerán los límites de la racionalidad. Empero la ontología del management norteamericano mostró dos versiones a decir: el pragmatismo y la experimentación social (conductismo). Dentro de esta periodización, la teoría política se centra en el behaviorismo, como también en la teoría de los sistemas y en el campo de las políticas públicas el behaviorismo describe la acción del sistema a través del Black-box de Eastoniano.

El racionalismo instrumental corpus consiguiente de la escuela de las relaciones humanas y la escuela motivacional fue el management imperante durante cuatro décadas y se sustentó sobre la base de que el gerente tiene libre decisión para aplicar recetas en pro de su saber administrativo (bajo el supuesto de liderazgo). La función directiva managerial de mediados del siglo veinte, fue de influjo vitalista, además esta no deviene del liberalismo político democrático, sino de la síntesis sociológica y de los aportes en clave del funcionalismo sobre el sustento de la teoría de las elites (soporte teórico de los denominados autores malditos ${ }^{16}$ ) y que luego se llamaría dominación de las elites, es decir, el gobierno societal recae en función de elites naturales ${ }^{17}$.

15 No es liberalismo político, es una argumentación que se nutre del vitalismo italiano y del romanticismo pangermánico.

16 Sustentan los modelos del autoritarismo bajo la figura de un líder o personaje carismático o un mesías que supuestamente resuelve los problemas de la sociedad originados de una crisis institucional.

17 El problema de este modelo es que el líder nunca forma cuadros de sucesión política, sumado al hecho que estas dictaduras no permiten que las capas bajas de la sociedad asciendan políticamente en el acceso al poder. 
Así como sigue siendo válido académicamente el escenario pragmatista en el management público, son igualmente válidas las corrientes vitalistas en relación a la libertad natural del decisor respecto a la toma de decisiones (como un objeto válido del liderazgo), esta corriente corrobora desde una versión integral naturalista el mundo de la vida, además metodológicamente hablando el vitalismo es muy casualista en relación del porqué ocurren los fenómenos sociales a partir de cuestionarse sus raíces u orígenes.

En el management de influjo paretiano el liderazgo no es de corte racional, el liderazgo aparece como una acción humana guiada por un impulso natural, siendo este la función directiva de los managers, además los gerentes son capaces de tomar decisiones libres e informadas, a tal punto que los altos mandos de la organización conducen a esta. A partir de aquí, entra a jugar también el tema de la intuición decisional denominado "naturalismo" que apunta a la noción de equilibrio social en la medida que se ajusta a la división natural de gobernantes y gobernados ${ }^{18}$. Tan naturalista es pues esta propuesta que se traslada a los campos de la psicología experimental bajo el rótulo de interpretación cognitiva de carácter constructivista obviamente naturalista al ser este una práctica humana.

Ahora bien, el sustrato teórico del círculo paretiano formalizó y construyó el modelo vitalista del corporativismo como una especie de antítesis política del marxismo y del socialismo radical, es decir un corporativismo de carácter institucional muy en las lógicas instrumentalistas de preservación del statu quo en términos del poder, lo que implica en términos generales, toda una teoría del equilibrio de carácter estructural-funcionalista ${ }^{19}$.

Por ello, el Nacionalsocialismo Alemán de los años treinta tiene un influjo directo de la corriente filosófica Vitalismo, como prueba de ello es la política de su teoría vital, propósito que se engendró a la figura de una raza superior con rasgos arios, es decir, es la supremacía de la teoría vital la que con su discurso hegemónico eliminó la diferencia. En términos objetivos de la política ${ }^{20}$ se planteó una Alemania para alemanes (por esa política murieron judíos, homosexuales, gitanos, marxistas, etc.). El sustento ideológico y metafórico de la teoría vital ve a las otras razas diferentes a la aria (pangermánica) como una plaga, y al ser estas una plaga, se entiende que, en el

18 La terminología dual: elites-masa, dirigentes y dirigidos, operadores y decisores, enriquece el discurso del poder empresarial bajo esquemas de comunicación.

19 Se entendería entonces que la teoría del equilibrio es una teoría armónica político-societal y/o una perspectiva de bio-poder o bio-política naturalista.

20 Esta política se autodenominó Estado de Guerra. 
análisis del discurso político del Nacionalsocialismo, a las plagas hay que eliminarlas (como las cucarachas) dado que las plagas son el origen de todos los males del mundo.

De igual forma, el Nacionalsocialismo Alemán tiene un influjo romántico21, muy opuesto a las posturas pragmático-racionalistas francesas e inglesas (donde para ellos, el sujeto racional es un ser individual), mientras que las posturas románticas del siglo decimonónico plantean la figura de un hombre en un contexto comunitario o bajo la figura metafórica del espíritu del pueblo, por esto se entiende con mucha más razón por qué surge la palabra Volkswagen (el carro del pueblo). La empresa Volkswagen nace en el contexto del Nacionalsocialismo Alemán. Ahora desde el análisis del discurso, si se analiza entre líneas "el espíritu del pueblo" como variable de poder o política, significa: un gobierno del pueblo, es decir, un gobierno de todos unidos, una causa común, (por lo tanto, un solo partido), lo que implica en términos reales, la negación de la democracia, como en efecto ocurrió.

Por lo tanto, una causa común, implica a su vez una singularidad común, un objetivo común, por ello el romanticismo se sincroniza en clave con el vitalismo, en una relectura simple esto significa en términos generales, una Alemania pangermánica bajo el sustento de una raza superior (supremacía vital), en este supuesto en medio de una crisis como fue la Primera Guerra Mundial se edificó toda la ideología del Tercer Reich bajo el testamento político de Mein Kampf (Mi lucha de Hitler).

Hay que agregar también, que este equilibrio societal requiere la administración de un líder mesiánico que guie al pueblo ante la crisis y lo encauze con destino a la tierra prometida. En este tipo de estructuras donde la comunidad está bajo la sombra del líder se le conoce políticamente como oligarquía. Sin embargo, hay que recordar que todo esto es producto también de la crisis política como económica y social que estaba viviendo Alemania durante la década del veinte y que ante la inminente llegada del comunismo desde Rusia, para las elites políticas, económicas e industriales, el Nacionalsocialismo era la única opción a apoyar y patrocinar. En términos políticos el Nacionalsocialismo Alemán era la reivindicación del pueblo pangermánico vitalista ante el ridículo como deshonra del tratado de Versalles y sirvió también como muro de contención romántica que eliminaría a toda costa la infiltración del marxismo en Alemania. Como se puede notar, el gobierno de elites es una prueba más

21 El romanticismo alemán se determinó en todos Ios planos culturales como en: Wagner en la música y Goethe en la literatura. 
de corporativismo de Estado. Las consecuencias nefastas de este tipo de estructuras la historia las ha escrito hasta la saciedad, cosa que no contemplaré aquí en este documento.

\section{EL POSTMODERNISMO Y LA POLÍTICA}

El postmodernismo es una corriente intelectual desde 1960 que hace alusión a una postura crítica de la razón pragmatista en la era de lo que se consideró moderno y modernidad, y además que surge como producto y consecuencia ante las promesas incumplidas por esta cosmogonía llamada modernidad, en la cual de manera irreal estos principios fueron sustentados bajo expresiones vigorizantes como el bienestar, el progreso, el crecimiento económico, la superación de la pobreza, etc. Es decir, conceptualizaciones que se quedaron cortas ante su incumplimiento en la era dizque de la modernidad, cuestionando si se quiere también el postulado del raciocinio humano ante dos guerras mundiales tan atroces y devastadoras. De igual manera, el postmodernismo se ha cuestionado también al totalitarismo como al capitalismo, y al mismo bienestarismo por las razones antes descritas.

Desde las épocas en mención (1960), se cuestiona también desde lo político las formas de gobierno en la sociedad y estas pueden presentarse con o sin democracia. Ahora bien, el gobierno convencional se expresa en el ámbito de la gestión como una perspectiva interiorizada en la vida política de una sociedad, como plantea Aguilar (2006), en sí las formas de gobierno dan cuenta de un Estado desbordado, burocrático y desarrollista, el cual tiende a estar inmerso en malas prácticas administrativas, como lo son la corrupción y el clientelismo. Esta tipología de gobierno expone un arraigo en el modelo legal racional, en el cual tanto el Estado como los sujetos que en él actúan tienden a estar definidos mediante rutinas que responden a costumbres en las estructuras, y que conllevan a que el accionar sea predecible y dirigido bajo una misma conceptualización.

Este gobierno se presenta como unilateral, dominando en él una serie de actores que buscan planificar y desarrollar su perspectiva partiendo de su contexto, sin ampliar el margen de su mirada hacia los demás actores que componen la sociedad. Debido a esto, su composición estructural es tradicionalmente piramidal (bajo un enfoque top-down) además jerarquizado al estilo de la "ley de hierro de la oligarquía" (Michells), planteando desde la elite de la burocracia las soluciones a las problemáticas que surgen de arriba hacia abajo, sin tener en cuenta a la base social en la cual inciden sus decisiones. Ahora bien, este proceso dada su estructura no permite la intervención de ningún otro actor, más que los que se encuentran en la cúspide de la pirámide. 
Pese a que este gobierno tiene presente que debe adaptarse a un contexto cambiante, y debe resolver una serie de problemáticas, su limitada perspectiva marcada por los actores que en él cohabitan (elites - terratenientes) conlleva a que los problemas aumenten, pues buscan solucionar las cuestiones que los afectan en sí, sin tener en cuenta las externalidades que viven los demás miembros sociales. Claro está, que al ser decisores y tener unos roles definidos, con el fin de no perderlos, los integrantes tienden a buscar una serie de apoyos políticos por lo cual inciden en malas prácticas administrativas.

Es precisamente en Downs (1957) que se logra comprender refinadamente que el dirigente político y el administrador público (burócrata) no son perfectos altruistas ni tampoco filántropos comunitarios, dado que no les interesa maximizar ni mejorar el bienestar de la sociedad, ya que a este tipo de sujetos que lideran procesos político-administrativos solo le interesa el dinero, el prestigio y poder que supone gobernar.

Frente a las grandes críticas planteadas en este documento hacia el modernismo, el gran cuestionamiento desde la filosofía política contemporánea es: ¿qué es lo justo? Si hemos analizado que el modelo económico no es funcional, si los gobiernos no son funcionales y la sociedad no está progresando en el esquema del bienestarismo, entonces, ¿cuál es el concepto de justicia? Esta pregunta es el dilema central en el abordaje de la teoría de la justicia de John Rawls hacia el año de 1970, además nuestro autor se encuentra inmerso frente a la dualidad entre el libertarianismo radical leseferista y el utilitarismo bienestarista. En vista de ello y de manera alternativa, Rawls (2002) propone una teoría equitativa de lo justo, teniendo en cuenta que el punto de partida originario en la sociedad no es igual para todo el mundo y que las asimetrías sociales e institucionales existen. Por ello, la posición original es a Rawls como el contrato social es a Rousseau, en consecuencia a lo estudiado y analizado hasta aquí, Rawls (2002) termina siendo un contractualista porque se justifica su pensamiento en aras de un cambio social que por lo demás es utópico, pero que plantea que se requiere una posición original en la que los actores políticos deciden lo mejor para la sociedad tras un velo de ignorancia, en el cual se descargan de intereses personales y toman decisiones en función de transparencia para equilibrar las asimetrías de los más desfavorecidos en la sociedad bajo estrategias Maximin y al aplicarse esto se decide en principios de justicia. Al llegar a un acuerdo las instituciones y la sociedad frente a este modelo, los principios de justicia no serían inapelables. Para Rawls (1970) el modelo bienestarista-utilitarista debería cambiar dada la experimentación mental que está realizando a través de este modelo. 
Por su parte, los principios políticos liberales de libertad e igualdad han sido interpretados por diferentes autores desde diversas perspectivas, en el caso de Ronald Dworkin (1996) su postura se centra entre el liberalismo y el comunitarismo. Así mismo se inscribe en la tradición liberal tradicional al asumir que el Estado se constituye atendiendo las exigencias que generan los principios liberales, planteando que el modelo contractualista es débil en su perspectiva fáctica, ya que no tiene sustento vinculante; a la vez expone que su perspectiva moral presenta dificultades pues todos serían iguales en razón, lo que implica reconocer igualdad al ingresar al contrato, y no es posible pues la moralidad ordinaria impide no reconocer los intereses de los demás.

Para el mencionado autor, los principios políticos liberales deben fundamentarse en una ética liberal, que permita superar las dificultades del contractualismo fáctico y moral. Esto presenta dos problemas: que la ética propuesta sea atractiva para contener el consenso, y que ante la justificación de la neutralidad del Estado frente a las moralidades individuales, resuelva cómo incluir la multiplicidad de perspectivas morales individuales.

Al adentrarse a abordar la igualdad, presenta que la teoría de la justicia en su búsqueda de la igualdad plantea diferentes variables: rentas, bienestar, oportunidades y recursos; donde la igualdad en una implica la desigualdad en otra. También expone que hay dos grandes grupos entre los cuales se dividen las teorías igualitaristas: el de la igualdad de bienestar, que se caracteriza porque formula como guía la distribución, el bienestar de cada uno de los sujetos; y el de la igualdad de recursos, que plantea que esta se alcanza cuando los sujetos tienen bajo su control una cuota de recursos igual; en esta se centra Dworkin (1996) donde presenta un esquema básico del igualitarismo liberal.

La igualdad de recursos se refiere a la distribución igualitaria de recursos, teniendo presente dos condiciones: necesidad de satisfacer requerimientos básicos, y escasez de recursos. Para orientar su propuesta parte de dos presupuestos, el aceptar el principio igualitario donde el Estado debe actuar mejorando la vida de quienes gobierna y considerando igualdad para todos; y la coincidencia entre las conclusiones sobre el tema de la justicia y los principios de la ética liberal.

Su escogencia sobre la igualdad la sostiene de acuerdo con tres argumentos: primero, critica la idea de igualdad de bienestar ya que es inherente a cada sujeto, por lo que la idea de bienestar varía de acuerdo a cada individuo. 
Segundo, porque para definir un proyecto de vida y el bienestar es necesario conocer la cantidad de recursos disponibles; y tercero, porque las razones éticas a las cuales presenta tres objeciones: solo tiene en cuenta los intereses de las personas, lleva implícita la idea de que el bienestar es competitivo, y la concepción del bien y el valor humano parten del modelo del desafío.

Ahora, el mecanismo para detectar la igualdad es el test de la envidia en el cual se pregunta a cada uno si quedó satisfecho con lo adquirido, si este es superado con éxito se introduce en la subasta walrasiana, donde se distribuye la totalidad de recursos disponibles; teniendo como métrica los costos de oportunidad. De igual modo, sin dejar nada de lado en el caso del mundo regulado por el mercado donde las desigualdades cohabitan se presentan los seguros.

El test de la envidia presenta dos fases, una distribución inicial de recursos, y la manera diacrónica en cómo estos son distribuidos durante la historia de la sociedad. Para que la repartición sea justa, debe haber libertad para cada uno de los individuos que participan al escoger, aunque los recursos pueden ser entregados por un sujeto esto podría sesgar los niveles de satisfacción a cada receptor. Se permite la igualdad de posibilidad de adquirir, así como la división de recursos disponibles en lotes con un valor cada uno de acuerdo con el juego entre la oferta y la demanda, esta culmina al estar todos los participantes satisfechos.

La métrica para conocer los valores de los recursos son los costos de oportunidad, los cuales reconocen que el tiempo y los ingresos son limitados, así como las diferentes alternativas entre las que se pueden invertir estos. Como tal se refieren a las opciones que se dejaron pasar para escoger los recursos, partiendo de qué tan importantes son de encontrarse en manos de otros, y cuál es el valor que presentan según las capacidades y talentos de cada uno.

Debido a la multiplicidad de sujetos y sus diferentes características el Estado entra a intervenir para configurar las circunstancias correctas para la distribución, ya que no todos cuentan con los mismos talentos y capacidades. Es aquí donde se vislumbra la igualdad de recursos en condiciones de mercado, ya que se parte de que todos cuentan con capacidades y talentos iguales, empero la realidad no es así, y a la vez se tienen que asumir las consecuencias del modelo de vida escogido.

Las consecuencias o riesgos de la elección del modelo de vida o de los recursos escogidos durante la subasta se pueden dar, ya sea por suerte 
opción o suerte lata. La primera implica la aceptación de un riesgo aislado, calculado donde es posible ganar o perder; la segunda, los riesgos que no se han decidido tomar. Esta última puede convertirse en suerte opción mediante los seguros, así como estos pueden cubrir las desigualdades en cuanto a habilidades y capacidades.

Los seguros, según Dworkin (1996), cubren si se adquiere una discapacidad o riesgo durante la elección, así como si los talentos y capacidades son desiguales al momento de la distribución inicial, de esta manera se pueden dar seguros de acuerdo a las habilidades y discapacidades, los cuales pueden darse como pago durante la subasta o mediante un impuesto gradual de acuerdo a los ingresos individuales y el nivel de riesgo que cada uno presenta.

En el caso que durante la repartición inicial los riesgos aumenten por las diferencias entre habilidades se puede contar con un seguro de desempleo donde se tienen como patrones las personas más hábiles en ciertas actividades, y la medición del riesgo en la población media. Empero, se plantea que como los seguros pueden traer como externalidad negativa despreocupación estos deben ser deducibles, corriendo cada quien con una parte del valor del siniestro, o demostrar que no se percibe como un mecanismo adicional para ser acreedor a la indemnización por no tener ingresos suficientes. Para este último puede el Estado recaudar una renta y distribuirla en quienes menos ingresos presentan, un principio de subsidiaridad, que puede ser igual para todos, bajo el concepto de no ser excesivo con los de bajos recursos, o gradual.

Ahora para terminar, se expone el nexo entre libertad e igualdad ya que estos principios se conceptualizan entre sí, presentando como puente entre ambas una estrategia constitutiva, que es un sistema de libertades y prohibiciones. Con el objeto de hacer esto, desarrolla su argumento en tres partes, como actuaria la estrategia en un mundo ideal-ideal, la subasta; en un mundo real-ideal, técnico, pero no político; y en un mundo real-real, la realidad actual. Para esto retoma la libertad como libertad negativa en cuanto a que es la posibilidad de actuar sin interferencia de ningún otro sujeto, a lo que agrega Dworkin (1996) que para ello existe un conjunto de derechos a tener ciertas libertades.

Según el mundo ideal-ideal, donde es posible la subasta de todos los recursos existentes, se tienen presentes los principios de seguridad, abstracción, corrección, autenticidad, e independencia. El de seguridad expone que el sistema (estrategia) debe contar con normas que reduzcan la libertad para 
proteger la vida de los asociados y permitan controlar los recursos que han adquirido; la abstracción, donde se defiende la libertad de elección con base en el cálculo de los costos de oportunidades, que deben reflejar el costo real de los proyectos de vida que cada uno de los participantes en la subasta tiene para los otros.

Por su parte, el principio de corrección plantea la corrección de distorsiones surgidas en la subasta, por externalidades y costos organizacionales, aquí quien subasta puede limitar la libertad de elección. En cuanto a la autenticidad, se tiene presente que cada participante ha formado una personalidad, que lleva consigo una opinión, gusto e intereses mediante los cuales escoge; y el principio de independencia, se refiere a que la subasta se corrija para eliminar consecuencias en la distribución que conllevan a la discriminación de los grupos minoritarios.

El mundo ideal-real plantea el déficit de igualdad donde hay un déficit de recursos y uno de libertad, el primero expone la diferencia entre los recursos que una persona tiene actualmente y los que tendría si se hubiera realizado una subasta justa; y el segundo, las libertades que tiene son inferiores a las que tendría si su comunidad tuviese un sistema de libertades y prohibiciones. Para este mundo las medidas que se pueden tomar son las que disminuyen el déficit de igualdad de unas personas sin aumentar el de otras.

Ahora, el mundo real-real se distingue porque hay una falta de compromiso político, individual, donde hay grandes diferencias, y las posibilidades técnicas son limitadas. En este el déficit de libertad se mide al analizar la libertad individual y la que se tendría en una situación igualitaria defendible $\mathrm{X}$. Integrando en su conceptualización el principio de victimización donde se es víctima de acuerdo al valor de su libertad, la cual es menor que en una distribución defendible.

De otra parte, Robert Nozick (1990) examina las cuestiones que subyacen en la tesis de que las restricciones morales indirectas limitan el comportamiento individual, para el desarrollo de esto aborda alrededor de nueve apartados como son el Estado mínimo y el Estado ultramínimo; las restricciones morales y fines morales; ¿Por qué restricciones indirectas?; restricciones libertarias; restricciones y animales; la máquina de experiencias; la indeterminación de la teoría moral; ¿en qué se basan las restricciones?; y el anarquista individualista.

Al iniciar da cuenta de la diferenciación entre el Estado mínimo y el Estado 
ultramínimo, planteando al primero como un Estado gendarme, donde se da la protección y cumplimiento de los contratos, mientras el segundo es un orden social intermedio entre el esquema de las asociaciones de protección privadas y el Estado gendarme. En ambos existen una serie de derechos protegidos y un uso de la fuerza legítima para esto, empero en el segundo esta como una función legítima no aborda la violación de los derechos por ser ilegítima.

En el apartado restricciones morales y fines morales, Robert Nozick (1990) expone que un interés moral solo puede ser fin moral como condicionante de ciertos resultados o actividades, ahondando en una definición utilitarista de los derechos, donde las violaciones de derechos serían aceptadas bajo el condicionante de servir a un fin mayor, un beneficio, o para minimizar la cantidad de violaciones de derechos; siendo los derechos restricciones indirectas a la acción a realizar, así los derechos de otros determinan las restricciones de las acciones individuales.

Continuando con ¿Por qué restricciones indirectas?, en este expone que los sujetos no son el reflejo de su fin sino que también son medios, así se presentan como herramientas con condiciones inviolables, de las cuales dan cuenta las restricciones. Al tratar el apartado de las restricciones libertarias, expresa que las restricciones morales indirectas reflejan el hecho de que ningún acto moralmente compensador puede tener lugar entre los sujetos, no existen sacrificios compensadores.

Así pasa a hablar de las restricciones y animales, donde a estos últimos se les debe dar importancia en las deliberaciones que los sujetos realizan de sus actos, si estas influyen o inciden en causales de daño o dolor conllevando a una consecuencia moral directa. De este apartado también conjetura que los individuos que agredan a los animales pueden ser considerados como posibles agresores de los mismos individuos, ya que puede que su agresión traiga consigo placer. Empero una descripción destacable de este apartado es que aunque los seres humanos no pueden tener una violación de sus derechos en beneficio de otros, los animales sí pueden ser sacrificados, desde una postura utilitarista dado que no serían considerados sujeto de derechos.

Ahora bien, en el punto de la máquina de experiencias, da cuenta de que el sujeto no solo quiere hacer, experimentar sino que quiere ser cierto tipo de individuo pero sin limitarse en realidad. Con respecto a la indeterminación de la teoría moral, el autor nos plantea tres estatus morales para el sujeto: 
primero no puede ser sacrificado, dañado, ni degradado..., en beneficio de otros; segundo, solo puede serlo si esto trae beneficio a seres superiores en escala a dicho ser; y tercero, puede ser dañado, etc. en beneficio de seres de su mismo nivel o de superior escala. Con esto se presenta una jerarquización de los sujetos, la cual puede ser observada desde la conceptualización de los animales y las restricciones, ya que al ser estos inferiores como seres pueden ser sacrificados.

Para finalizar trata los apartados ¿En qué se basan las restricciones? y el anarquista individualista. En el primero expone que hay que considerar las cuestiones básicas sobre las que se fundamentan las conceptualizaciones morales, para lo cual entra a tratar las características de los individuos que limitan el accionar de los otros hacia ellos. Planteando que según la propuesta tradicional las características relacionadas con las restricciones morales son sensible y autoconsciente, racional, poseedor de libre albedrío, ser agente moral con capacidad para guiar la conducta a través de principios morales y de comprometer con limitaciones mutuas, tener un alma, y tener capacidad de regular y guiar la vida de conformidad con alguna concepción general aceptada.

En el apartado final expone que las maneras específicas por las que el Estado en un territorio castigue, o incurra en el control de las violaciones de derechos lo hace de igual modo en el caso de violar derechos legítimamente intrínsecamente inmorales. Pues al tener el monopolio de la fuerza y castigar a quienes lo violan, viola las restricciones morales indirectas de trato hacia los individuos.

En el capítulo séptimo "la justicia distributiva”, Nozick (1990) expone que no existe una distribución neutral, ni quien, de manera correcta facultado para ello, por lo cual en vez de plantear la conceptualización de la justicia distributiva es viable exponer un principio de justicia de las pertenencias; para desarrollar esto inicia con una primera sección, sobre la teoría redistributiva, donde señala su postura en cuanto a las pertenencias.

Según el autor, el objeto de la justicia de las pertenencias consiste en tres pautas: la adquisición original, la transmisión, y que las pertenencias solo hayan sido obtenidas de acuerdo a las dos primeras; de esta manera, la distribución sería justa al tener cada quien derecho a lo que se le distribuyó legítimamente. Empero, Nozick (1990) considera la adquisición por medios no sancionados para lo cual plantea el principio de rectificación, donde se 
expone lo que sucedería si la injusticia no ocurre con base en información histórica.

El carácter histórico entra en escena, al vislumbrar los principios históricos, ya que la teoría redistributiva de la teoría distributiva es histórica, y lo justo de la distribución depende de cómo se produjo. Para esto se sostiene que las acciones o circunstancias que ocurren pueden generar derechos o merecimientos, incluso estos pueden llevar a violación de derechos que conllevan a la rectificación. Ahora bien, para saber si la distribución varía de acuerdo con alguna dimensión natural se conceptualizan las pautas, que son principios no históricos pero que consideran acciones pasadas que generan derechos diversos para evaluar una distribución; a partir de estos se puede explicar cómo surge la distribución inicial.

El mantener una pauta requiere que se intervenga constantemente a las personas para impedir que realicen a su voluntad transmisión de recursos. Aunque como se puede vislumbrar, de acuerdo con Amarthya Sen (2002), el derecho a las pertenencias otorga el derecho a disponer de ellas, pudiendo cada quien ejercer dicho derecho como decida.

Se debe tener presente que desde la teoría redistributiva, la redistribución comprende la violación de los derechos de los individuos, por lo cual, como se puede observar en Locke (1990), hay que asegurar que con el accionar individual la situación de los otros no empeore, o que con la distribución se deje lo suficiente e igualmente bueno a los otros en común, que se puede llegar a plantear desde la perspectiva del óptimo paretiano.

El autor en el desarrollo del capítulo tiene presente que alguien puede empeorar su situación debido a la apropiación realizada por otros, así puede perder la oportunidad de apropiarse o no puede usar libremente lo que antes podía. De igual modo, es destacable que el autor no solo presenta en la distribución el tema de las pertenencias sino de la libertad, ya que expone la violación de la estipulación del principio de justicia de adquisición al limitar la libertad de los otros, empeorando con ello su situación.

La estipulación como tal plantea la exclusión de la apropiación, la limitación de los derechos de propiedad con el objeto de evitar empeorar la situación colectiva, dado que no solo quienes favorecen la propiedad privada necesitan 
legitimarse teóricamente sino también los que apoyan la propiedad colectiva.

De esta manera, en el desarrollo del capítulo Nozick (1990) expone su perspectiva sobre las pertenencias, las cuales pueden ser adquiridas originalmente o mediante transmisión, siendo esto legítimo, si históricamente no hay ninguna rectificación, se cumple con pautas en el caso de la distribución pautada y no se limita la libertad de los sujetos, respetando los derechos de propiedad.

\section{CONCLUSIONES}

Lo que se ha podido analizar en el desarrollo de este documento en su versión de la larga duración histórica de la filosofía política (o de la teoría política), dentro del enfoque de la transdisciplinariedad en las Ciencias Sociales, es que la variable transversal como convergente a ella, y que marca una tendencia en el desarrollo su paradigmático es el contractualismo y el neo-contractualismo dada sus diferentes versiones en medio de la dualidad: "Estado y mercado", el cual explicaremos a continuación.

En primer lugar hay una versión inicial en torno al Estado, cual es claramente visible desde la concepción de Hobbes (1994) entorno al "Leviatán" porque este se desarrolla en la era en que se establece el absolutismo monárquico, y que al mismo tiempo también se estan dando en Europa los primeros pasos hacia el establecimiento y la conformación del ideario político de los contextos de Estado-Nación en los territorios y estas posturas aparte de ser políticas territoriales y fundacionales son también económicas, esto se reflejó básicamente en el desarrollo del mercantilismo como fuente del fortalecimiento del Estado. Por ello la tesis central de los mercantilistas giró alrededor de que un Estado es más fuerte, si obtiene ganancias fruto del comercio internacional a través de una balanza comercial favorable. Por lo tanto, en estos escenarios europeos ya se está pensando en una noción de Estado que lo controla todo y que es coherente en su versión absolutista.

De otra parte, se muestra la otra cara de la moneda (en relación al mercado) y esta aparece en Locke (1990), donde ya se presenta una posición distinta y contradictoria al absolutismo monárquico y que entiende desde una postura más cargada de intencionalidad racional que el Estado necesita sujetos libres como autónomos para desarrollar instituciones y que estas deben ser respaldadas bajo el contexto estatal de la división de poderes ya que permiten la libre 
deliberación entre actores racionales que deciden lo mejor para la sociedad. De igual forma en el contexto económico el leseferismo es su núcleo fundamental. Tan imperante fue esta forma de ver el mundo liberal, que el modelo económico de la mano invisible smithiana duró aproximadamente alrededor de 150 años entre 1776 y 1929.

Después de la crisis internacional del capitalismo del año de 1929, el contexto político giró del mercado hacia el Estado porque la mano invisible fracasó y además porque eran necesarias las acciones de regulación en pro del bienestar social, las cuales solo las podría garantizar en este caso el Estado. En este contexto político al Estado se le denominó paternalista o proteccionista porque podría resolver las problemáticas de la sociedad en crisis mediante la fórmula de políticas públicas del Estado a la sociedad. Empero, el modelo paradigmático estatal fracasa 40 años después porque incumplió los grandes metarrelatos en los que estaba instaurado e instalado sobre temas tan sensibles para la sociedad como el progreso, el bienestar y de una vida mejor. Cabe anotar que este tipo de utopías jamás se pudo medir y en los escenarios burocráticos públicos el impacto de las medidas de política pública en pro de ese mejor bienestar nunca se pudo calcular, por ello al no tener factor de medición claro y evidente, se puso en un manto de dudas al modelo de Estado benefactor utilitarista como factor de desarrollo social. Frente a esta situación aparecen autores angloparlantes como John Rawls en la década de los setenta que se preguntan entonces ¿qué es la justicia?

Al sucumbir el Estado de bienestar, los argumentos teóricos desde la filosofía política ya propugnaban y establecían desde los años setenta un retorno a las ideas liberales del siglo XVIII, bajo contextos como el de la aldea global, (la globalización) y del nuevo imperio (otra versión de la mano invisible) de Hardt y Negri (s.f.), así como también la reducción burocrática hacia un Estado mínimo de Nozick (1990), y del retorno de la subasta walrasiana del mercado desarrollada por Dworkin, es decir, es el retorno inminente a la sociedad del mercado autorregulado y donde el sujeto como ser racional es responsable de su desarrollo social, político y económico. Este Estado solo protege a sus ciudadanos en las lógicas de los autodenominados Estados sociales de derechos. No obstante, se reconoce esta versión del Estado en función de súbditos bajo imperios como la ONU que le transfieren meta-políticas en su versión paradigmática imperante. Hoy los territorios tienen un imperio que les ordena políticamente su accionar institucional en lo político, en lo económico y en lo social. 


\section{REFERENCIAS BIBLIOGRÁFICAS}

Aguilar, L. (2006). Gobernanza y Gestión Pública. México: Fondo de Cultura Económica.

Aktouf, O. (2001). La administración: entre tradición y renovación. Cali: Artes Gráficas del Valle.

Alvesson, M. (1993). El juego de las metáforas. En. Hassard y Paker (Comps), Posmodernism and Organizations. Londres: Sage.

Aristóteles (2001). Política. Libros I y III. Barcelona: Ediciones Folio.

Borrero, A. (1993). La interdisciplinaridad. En: Política y Gestión Universitaria, (13).

Cano, L. (2008). Gobernabilidad y gobernanza en Medellín: ¿modelos excluyentes o complementarios de la acción pública en el escenario local? En: Revista Estudios de Derecho.

Chanlat, A. (1984). La multicomplementaridad en el conocimiento y en la acción. En: Gestión et culture d'entreprise. Le Cheminement d'HydroQuébec, cap. 10 (pp. 203-223). Québec-Amérique, Montréal. Traducción de Clara María Cavagnaro (ESAN, Lima, Perú).

Chevallier, J. (1979). Mein Kampf (Mi lucha), de Adolfo Hitler. En: Los grandes textos políticos. Madrid: Aguilar.

Dobb, M. (1971). Estudios sobre el desarrollo del capitalismo. Apéndice. México: Editorial Siglo XIX.

Downs, A. (1957). An economic theory of political acción in a democracy. Journal of Political Economy, 110.

Dworkin, R. (1996). La comunidad liberal. Bogotá: Universidad de los Andes.

Gomperz, T. (1955). Greek thinkers: A history of ancient philosophy. Vol 1. L (Magnus). New York: Humanities Press.

Gusdorf, G. (1960). Pasado, presente y futuro de la investigación interdisciplinaria. En: Interdisciplinariedad y Ciencias Humanas.

Hardt, M. \& Negri, A. (s.f.). Imperio. Barcelona: Paidós.

Hobbes, T. (1994). Leviatán. Leviatán I y II. Barcelona: Editorial Altaya.

Kafka, F. (1980). La metamorfosis. Madrid: Alianza Editorial.

Locke, J. (1990). Segundo tratado sobre el Gobierno Civil. Madrid: Alianza Editorial.

Marx, K. (1995). El capital. España: Fondo de Cultura Económica.

Max Neef, M. (1996). Fundamentos de la transdisciplinariedad. Santiago de Chile: Universidad Austral de Chile.

Morin, E. (2006). Sobre la interdisciplinariedad. En: Revista Sociología y Política, Año IV(8).

Nozick, R. (1990). Anarquía, Estado y utopía. México: Fondo Económico de Cultura.

Rawls, J. (2002). La justicia como equidad: Una reformulación. Barcelona: Paidós.

Rousseau, J. (1989). Del contrato social o principios del derecho político. 
Madrid: Editorial Alianza.

Sabine, G. (1994). Historia de la teoría política. 3era. edición. México: Fondo de Cultura Económica.

Sen, A. (2002). Economía de bienestar y dos aproximaciones a los derechos. Traducción de Everaldo Lamprea Montealegre. Bogotá: Universidad Externado de Colombia.

Vernant, J. (2001). El individuo, el amor y la muerte en Grecia. Capítulo El individuo en la ciudad. España: Paidós.

Weber, M. (1995). La política como vocación. En: El político y el científico. España: Editorial Atalaya. 